Wolfgang Forker

Elektrochemische Kinetik 



\section{Elektrochemische Kinetik}

von

Prof. Dr. rer. nat. habil. WOLFGANG FORKER

Technische Universität Dresden

2. bearbeitete Auflage

Mit 39 Abbildungen und 1 Tabelle 


\section{ISBN 3-05-500486-8}

Erschienen im Akademie-Verlag Berlin, Leipziger Straße 3-4, Berlin, DDR-1086 (c) Akademie-Verlag Berlin 1989

Lizenznummer: $202 \cdot 100 / 518 / 89$

Printed in the German Democratic Republic

Gesamtherstellung: VEB Druckhaus „Maxim Gorki“, 7400 Altenburg

Lektor: Fritz Schulz

LSV 1215

Bestellnummer: $7638220(5598)$

02800 